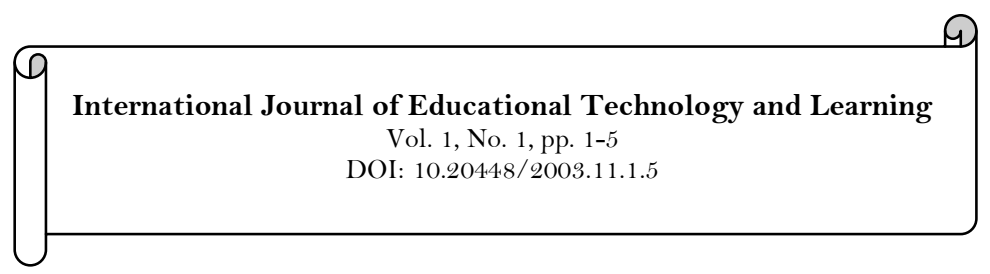

\title{
The Importance of Knowing and Applying the Standards in A Scientific Research
}

\author{
Irida HOTI ${ }^{1}$ \\ Rina MUKA ${ }^{2}$ \\ ${ }^{1}$ University “Luigj Gurakuqi” Faculty of Social Sciences, Albania \\ ${ }^{2}$ University “Luigj Gurakuqi”, Faculty of Sciences of Education, Albania.
}

\begin{tabular}{|c|c|}
\hline Abstract & \\
\hline $\begin{array}{l}\text { The importance of knowing and applying the standards in scientific } \\
\text { research at University is of a great value, because it first avoids } \\
\text { plagiarism and secondly shows originality. In this paper we will } \\
\text { represent the scientific research standards as one of the principal } \\
\text { criteria for student's evaluation. Scientific research as an original } \\
\text { presentation of a course task or dissertations at university requires } \\
\text { being effectively based on standards, which show the quality of the } \\
\text { written work. So a variety of exercises that provide serious practice } \\
\text { in both learning and writing process and developing a final written } \\
\text { paper can affect the quality of a written paper. An important feature } \\
\text { is the reference on which a researcher is relied on. This reference } \\
\text { must be used effectively into the body of the writing, as to fit with } \\
\text { the whole idea of the writing. If writing is considered a repeated } \\
\text { process with progressive and regressive phases, in this way must be } \\
\text { conceptualized the first difficulties faced by the new researcher (our } \\
\text { student). So the approaches and methods used in doing a scientific } \\
\text { research the application of its standards lead to a oreat evaluation. }\end{array}$ & $\begin{array}{l}\text { Licensed: } \\
\text { This work is licensed under a } \\
\text { Creative Commons Attribution } \\
\text { 4.0 License. }\end{array}$ \\
\hline
\end{tabular}

\section{The Importance of Scientific Research}

Scientific research is a systematic process that focuses on being objective and in gathering information for analysis so that the researcher can come to a conclusion. The scientific research standards as one of the principal criteria for student's evaluation are of a great value. Its importance starts by the first steps of the research, so by choosing a topic, exploring in the proper research field, reading as much from the same topic, then writing about the topic with an original idea. Knowing and applying scientific research standards at University is useful and a necessity. "The first advice that can be given to learn how to write, is to read as much as we can in the field we want to search, especially from the well known writers of that field. Reading helps 'to absorb' without understanding the technique of writing, the structure of such writings and the progress of their process." (Memushaj, 2005).

- What is a scientific research?

The authors of the book "The methodology of scientific research", Kazazi and Hoti state that the scientific research is a totality of questions for a single topic, as:

- How to choose the scientific research method?

- How to formulate the topic?

- How to develop a platform?

- How to plan the theme of a scientific research at a limited time?

- How to use the references into the body of the research?

- How to gather and analyze the literature?

- How to write the bibliography?

All these questions are related to a Bualo's saying: “Before learning to write, learn to think". (Kazazi, Hoti, \& Hysa, 2007)

\subsection{The Steps of a Writing Process}

"Writing means to own the normative expressive manner, always to experience orthography, grammar and punctuation expressiveness etc. Writing means to leave traces of your ideas, thoughts and culture." (Shkurtaj, 2008) 
Folse, Vokoun and Solomon in the book 'Writing paragraph' (1999) emphasize seven steps of writing process:

1. Choosing a topic

2. Brainstorming

3. Rough draft

4. Cleaning up the rough draft

5. Peer editing

6. Revising the draft

7. Final draft

These steps are closely related and each one has its importance. The revising draft is the most decisive step which is focused on:

- reacting to the comments on the peer editing sheet,

- rereading the paragraph and making changes,

- rewriting the paragraph one more time (Folse, Vokoun, \& Solomon, 1999).

Another model of research steps within the scientific method of inquiry is by Fraenkel and Waller in the book "How to design and evaluate research in education" on which the scientific research involves a systematic process that focuses on being objective and gathering a multitude of information for analysis so that the researcher can come to a conclusion. This process is used in all research and evaluation projects, regardless of the research method (scientific method of inquiry, evaluation research, or action research).

1. Identify the problem or develop a research question

2. Review the literature

3. Clarify the problem

4. Clearly define terms and concepts

5. Define the population

6. Develop the instrumentation plan

7. Collect data

8. Analyze the data (Fraenkel \& Waller, 2008)

There are diversity of scientific research models to advice the steps of writing. We focused on two of them, because they show two different ways of researching.

\begin{tabular}{l|l}
\hline Seven steps of writing process & \multicolumn{1}{c}{ Research steps } \\
\hline 1.Choosing a topic & 1. Identify the problem or develop a research question \\
2. Brainstorming & 2. Review the literature \\
3. Rough draft & 3. Clarify the problem \\
4. Cleaning up the rough draft & 4. Clearly define terms and concepts \\
5. Peer editing & 5. Define the population \\
6. Revising the draft & 6. Develop the instrumentation plan \\
7. Final draft & 7. Collect data \\
& 8. Analyze the data \\
\hline
\end{tabular}

The steps of writing process vary from the type of research we want to make. "Writing is a creative process, which seeks to write the ideas, give meaning, structure and analyze. These all underline creativity. Murray and Moore (2005)

\section{The Types of the Scientific Research}

At university the students face mostly a course framework as a scientific research, but they also must practice different types of writing, as: how to prepare an article, how to write a Review of a book, a Review of a scientific research, a Poster, a CV, a Project etc. At the discipline of Academic writing the students are used to practice different ways of writing, by activities at auditorium. Each type of writing depends on its outline structure. A report's structure differs from a book review or a poster etc.

- $\quad$ Some Structures Used in University Writing

Crème and Lea, in the book "Writing at University", represent some structures used in writing:

Chronology writing,

Description writing,

Cause-effect writing,

Compare/contrast writing

Summary writing,

Analysis writing,

Evaluating writing. Murray and Moore (2005) 
From the above structures we find the most useful and practiced for our students the Analysis writing which requires to search and to ask questions such as: - What does this mean?, - Why is this important?, How does this work, $\bullet$ How is this put together?, $\bullet$ Can you explain this?.

When a student is able to give answers to these questions, then he is able to write every other writing type.

- $\quad$ Key Elements of University Writing

The authors Crème and Lea also give key elements of university writing:

- Developing an argument

- Linking theory and evidence

- Drawing a conclusion

- Analyzing

- Being critical

- Developing a central idea

- Processing information

- Incorporating facts

- Correct terminology

- Logical order

- Use of evidence to support an argument

- Use of primary texts

- Use of quotations

- Drawing on personal experience

- Expressing own opinions

- Using personal interpretation

\title{
3. The Importance of References (Avoiding Plagiarism)
}

"The concept of plagiarism is very complicated, not least because it is often very difficult to decide where an 'original idea' came from" (Creme \& Lea, 2008).

The references show originality to the paper.

They are essential in a scientific research because are a source for the new researcher, who relies on them. The reference must always be referred to avoid plagiarism and must be used effectively into the body of the writing, as to fit with the whole idea of the writing.

References can be: footnote, endnote or in APA Style.

- Footnote reference is frequently used and it is easier for the reader to understand the source of the reference quoted in that page. In this reference is given the name and the surname of the author, the title of the book or the article in italic, the year of publication, the Publishing company and the page referred.

\author{
Footnote \\ - Richardss and Richard (2000). Dictionary of language teaching and applied linguistics, Pearson \\ Education, p.456.
}

These references are also used to explain a term or to give an extra explanation for an issue.

\section{Footnotes for the explanation of the terms research, evaluation research $n$}

the study of an event, problem or phenomenon using systematic methods, in order to understand it better and to develop principles and theories about it.

Richards (2000)

evaluation $n$

in general, the systematic gathering of information for purposes of decision making. Evaluation may use quantitative methods (e.g. tests), qualitative methods (e.g. observations, ratings (see RATING SCALE)), and value judgements.

Richards (2000)

- Endnote references are the references at the end of the book, chosen from the researcher for technique issue. Maybe this is easier for the author, when the sayings are repeated from the same author. 


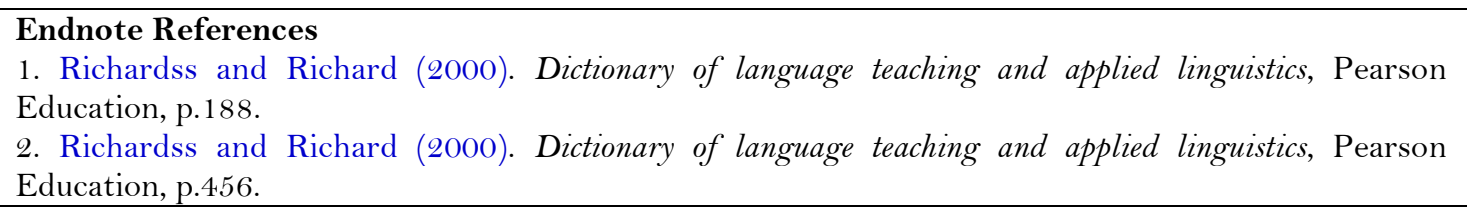

- $\boldsymbol{A P A}$ style, is mostly used nowadays, it is practical. It is used into the body of a paper after the quotation, in brackets, by identifying the surname of the author, the year published and the page quoted.

\begin{tabular}{l}
\hline APA Style References \\
"We can not write without having a totality data, which will be an object of analyses" (Memushaj, 2005). \\
\hline
\end{tabular}

\section{The Evaluation of a Student's Research Based on Standards}

It is comprehensive that a student's paper can't be at the level of a real researcher, but it must respect the writing standards and must be evaluated as such. "We can not write without having a totality data, which will be an object of analyses" (Memushaj, 2005).

To evaluate a paper the professor must be clear to the student that his paper will be revised based on:

Title:

Problems treated in the article:

Scientific value and the contribution of the paper:

The literature used:

References:

Do the author's conclusions represent interest?
Which is the value of the article?

Is the paper original?

Is it interesting?

Does it express the main aim of the author?

How does it answer to the scientific argument?

How are used?

Do they fit to the body of the article?

Before preparing the paper and his article to be evaluated by the professor or editorial board the student must be included in a variety of exercises that provide serious practice in writing process and which affect the quality of the written paper later.

So in our auditorium, this writing practice we focus on some models as below:

Model Practice 1

Write an abstract for a chosen topic by yourself or given by the professor by following the rule:

1.From the title to the literature.

2. From the literature searching toward formulating a title.

Model Practice 2

Brainstorm a topic.

Write as much as you can for the topic.

No grammar rules.
Model Practice 4

Find an article in a journal or magazine.

Prepare a report by expressing your opinions and personal interpretation.

Try to be critical.

Model Practice 5

Evaluate a scientific research paper focusing on:

-references

- idea treatment

- arguments given in the article

Model Practice 3

Find references for a given topic.

Write a paragraph on which the reference fits into the body of the paragraph.
Model Practice 6

What other ideas for a new research have come to your mind after searching and working for your paper?

The evaluation of a paper is important based on the experience of the researcher. "For the theoretician of the scientific research methodology is not important the topic of the paper as the experience gained on working it" (Eko, 1997). 


\section{Conclusion}

Scientific research as an original presentation of a course task or dissertations at university requires being effectively based on standards, which show the quality of the written work.

A variety of exercises that provide serious practice in both learning and writing process and developing a final writing can affect the quality of a written paper.

The Scientific research standards at University are the fundamental issue into the corpus of the disciplines studies.

The writing process even difficult and complicated, is an important way for every academic, teacher, researcher and scholar. "If writing is considered as a repeated process with progressive and regressive phases, in this way must be conceptualized the first difficulties faced by the new researcher (our student)." Hoti and Hysa (2010)

The approaches and methods used in a scientific research, the respect toward its standard lead to a great evaluation.

\section{Recommendation}

The recognition of scientific research standards by both the professor and the students:

- Leads to a real evaluation, avoiding the uncertainties associated to the assessment and the possible misunderstandings between them.

- Help the students make a self-assessment to predict the professor's assessment or criticizer's view.

\section{References}

Creme, P., \& Lea, M. R. (2008). Writing at university (3rd ed.). Buckhingam: Open University Press.

Eko, U. (1997). How to do a diploma work. Tirana: Publishing Efforts.

Folse, K., Vokoun, A., \& Solomon, E. (1999). Great paragraphs. Boston, New York: Houghton Mifflin Company.

Fraenkel, J., \& Waller, N. (2008). How to design and evaluate research in education. McGraw-Hill, Higher Education.

Hoti, I., \& Hysa, M. (2010). Academic writing, ideas, concepts, models. Shkodra: Camaj-Pipa.

Kazazi, N. J., Hoti, I., \& Hysa, M. (2007). Academic writing. Shkodër: Camaj-Pipa.

Memushaj, R. (2005). Standard Albanian. Tirana: Toena: Publications.

Murray, R., \& Moore, S. (2005). The handbook of academic writing: Open University Press.

Richards, S. (2000). Dictionary of language teaching and applied linguistics: Pearson Education.

Richardss, J., \& Richard, S. (2000). Dictionary of language teaching and applied linguistics. Pearson Education.

Shkurtaj, G. J. (2008). How to write in Albanian. Tirana: Toena Publishing. 